\title{
可 \\ WILEY \\ Wiley Interdisciplinary Reviews: \\ Energy and Environment
}

\section{Transmission Planning for Wind Energy: Status and Prospects}

\begin{tabular}{|c|c|}
\hline Journal: & Wiley Interdisciplinary Reviews: Energy and Environment \\
\hline Manuscript ID: & WENE-045 \\
\hline Wiley - Manuscript type: & Overview \\
\hline $\begin{array}{r}\text { Date Submitted by the } \\
\text { Author: }\end{array}$ & 17-Aug-2011 \\
\hline Complete List of Authors: & $\begin{array}{l}\text { Smith, J. } \\
\text { Holttinen, Hannele; Technical Research Center of Finland VTT, } \\
\text { Energy Systems } \\
\text { O'Malley, Mark; University College Dublin, Department of Electrical, } \\
\text { Electronic \& Communications Engineering } \\
\text { Burke, Daniel; University College Dublin, Department of Electrical, } \\
\text { Electronic \& Communications Engineering } \\
\text { Orths, Antje; Energinet.dk, Development Department } \\
\text { Dobschinski, Jan; Fraunhofer Institute for Wind Energy and Energy } \\
\text { System Technology (IWES), Division Energy Economy and Grid } \\
\text { Operation } \\
\text { Dale, Lewis; National Grid, Regulation Dept } \\
\text { Gomez-Lazaro, Emilio; Universidad de Castilla-La Mancha, } \\
\text { Renewable Energy Research Institute, DIEEAC/EDII-AB } \\
\text { Rawn, Barry; Delft University of Technology, Electrical Sustainable } \\
\text { Energy } \\
\text { Gibescu, Madeleine; Delft University of Technology, Electrical } \\
\text { Sustainable Energy } \\
\text { Estanqueiro, Ana; LNEG, Laboratorio Nacional de Energia e } \\
\text { Geologia, UESEO } \\
\text { Tande, John Olav } \\
\text { Zavadil, Robert } \\
\text { Osborn, Dale } \\
\text { Lasher, Warren } \\
\text { van Hulle, Frans } \\
\text { Korpas, Magnus; SINTEF, Energy Systems } \\
\text { Trotscher, Thomas; Statnett }\end{array}$ \\
\hline Keywords: & transmission planning, transmission policy, wind integration \\
\hline $\begin{array}{l}\text { Choose } 1-3 \text { topics to } \\
\text { categorize your article: }\end{array}$ & GDAA, GJAA, GKAA \\
\hline
\end{tabular}




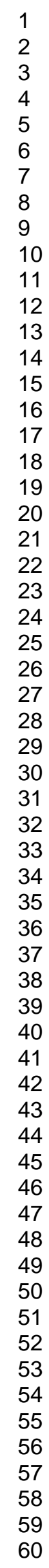

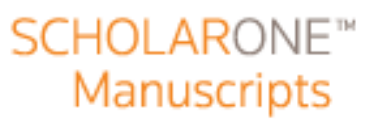

25

26

27
28

29

30

31

33

34

35

36

37

38

40

41

42

44

45

46

47

48

50

51

52

53

54

55

57

58

59

60 
Please select the appropriate article type (per your Contributor's Agreement) by double-clicking on the associated check box.

\begin{tabular}{|l|l|l|l|}
\hline$\square$ & Overview & $\begin{array}{l}\text { Overviews will provide a broad and relatively non-technical treatment of } \\
\text { important topics at a level suitable for advanced students and for researchers } \\
\text { without a strong background in the field. }\end{array}$ & $\begin{array}{l}4,000 \text { words } \\
\leq 10 \text { figures/tables } \\
\leq 50 \text { references }\end{array}$ \\
\hline$\square$ & $\begin{array}{l}\text { Advanced } \\
\text { Review }\end{array}$ & $\begin{array}{l}\text { Advanced Reviews, aimed at researchers and advanced students with a strong } \\
\text { background in the subject, will review key areas of research in a citation-rich } \\
\text { format similar to that of leading review journals. }\end{array}$ & $\begin{array}{l}6,000-8,000 \text { words } \\
\leq 16 \text { figures/tables } \\
\leq 100 \text { references }\end{array}$ \\
\hline$\square$ & Focus Article & $\begin{array}{l}\text { Focus articles are short articles, sometimes included within a larger article, } \\
\text { that describe specific real-world issues, examples, implementations, etc. } \\
\text { These articles will be technical in nature. }\end{array}$ & $\begin{array}{l}3,500 \text { words } \\
\leq 3 \text { figures/tables } \\
15-25 \text { references }\end{array}$ \\
\hline$\square$ & $\begin{array}{l}\text { Opinion } \\
\text { Opinions provide a forum for thought-leaders, hand-picked by the editors, to } \\
\text { provide a more individual perspective on the field in question. }\end{array}$ & $\begin{array}{l}3,000 \text { words } \\
\leq 6 \text { figures/tables } \\
15-25 \text { references }\end{array}$ \\
\hline $\begin{array}{l}\text { Editorial } \\
\text { commentaries }\end{array}$ & $\begin{array}{l}\text { provide an opportunity for editors to offer their own syntheses of broad areas } \\
\text { of research in a flexible and informal style; they are broadly comparable to } \\
\text { journal-style 'editorials'. We would expect to see an Editorial commentary } \\
\text { from the Editor in Chief in the launch issue of the WIRE, and occasional } \\
\text { contributions (no more than one per issue on average) thereafter. }\end{array}$ & \\
\hline
\end{tabular}

\section{Transmission Planning for Wind Energy: Status and Prospects}

\begin{tabular}{|l|}
\hline First author: Full name and affiliation; plus email address if corresponding author \\
*J. Charles Smith, UWIG; Charlie@uwig.org \\
\hline Second author: Full name and affiliation; plus email address if corresponding author \\
Dale Osborn, MISO \\
\hline Third author: Full name and affiliation; plus email address if corresponding author \\
Robert Zavadil, EnerNex \\
\hline Fourth author: Full name and affiliation; \\
Warren Lasher, ERCOT \\
\hline Fifth author: Full name and affiliation; \\
Emilio Gómez-Lázaro, Castilla La Mancha University \\
\hline
\end{tabular}




\section{Abstract}

This paper provides an overview of major transmission planning activities related to wind integration studies in the US and Europe. Transmission planning for energy resources is different from planning for capacity resources. Those differences are explained, and illustrated with examples from several regions of the US and Europe. Transmission planning for wind is becoming an iterative process consisting of generation expansion planning, economic-based transmission planning, system reliability analysis, and wind integration studies. A brief look at the policy environment in which this activity is taking place is provided.

Index Terms-- Transmission planning, transmission policy, wind integration.

At the beginning of 2011, nameplate wind capacity in the US had exceeded 40 GW, while that in Europe had risen to $86 \mathrm{GW}$. More than $35 \mathrm{GW}$ of wind capacity were added globally in 2010, and in spite of the continuing global economic slowdown, the prospects for continued development remain bright. However, one cloud on the horizon is the lack of sufficient transmission capacity to move the wind energy from the best wind resource areas, most of which are remote, to the distant load centers. A critical conundrum has been recognized in the transmission planning area, and is being dealt with at the 
regional, national, and international level. This is the situation where it may take 5-10 years to plan, permit, and construct a transmission line, while a wind project can be planned, permitted and constructed in 2-3 years. A remote wind project cannot be financed until the transmission access is provided, and the transmission line cannot be built with cost recovery certainty until the need for service from the wind plant is shown, thus setting up a scheduling conflict which cannot be resolved. At the regional level in the US, Texas has broken the logjam with the establishment of a Competitive Renewable Energy Zone (CREZ) process, which allows transmission to be built and paid for in advance of the construction of the wind plants. This model is being applied to other parts of the US and is beginning to be explored in Europe, for example for accessing the offshore wind power resources with the planned HVDC VSC offshore "sockets" that the German TSO's have been legally required to install for offshore wind power development zones in Germany.

\section{TRANSMISSION PLANNING FOR ENERGY RESOURCES}

\section{A. Traditional Transmission Planning}

Before deregulated markets and wind energy resources were available, generation was selected economically from a set of candidate generation types. The amount of generation of each type was chosen to produce the most economical mix of generation from the types available. A trade-off between the capital cost of a generator and the cost to produce energy determined the amount of any one type of generation. The magnitude of the total generation mix was chosen to meet the load plus some reserve margin economically. Transmission was planned based on meeting the peak load hour of the year, and was referred to as reliability-based transmission planning. This method solves problems associated with specific short-term needs, but does not address the issues associated with moving large blocks of renewable energy from remote locations to load centers.

Much of the US wind generation was installed in response to legislative requirements established through a state Renewable Portfolio Standard (RPS), while much of the continued growth of wind power in Europe has been driven by the success of various types of support schemes in different countries (notably the successful feed-in tariff system) linked to achieving mandatory renewables targets set by European legislation. Wind is a non-dispatchable energy resource, as opposed to the more traditional dispatchable capacity resource. As a renewable energy resource, its value is in displacing higher priced fossil fuels and reducing carbon emissions, as opposed to providing for system reliability requirements. As such, traditional capacity-based transmission planning methods need to be modified in recognition of the different attributes of this energy source. Remote wind locations may require substantial transmission with significant associated costs. In the capacity planning world, transmission does not have to be able to pay for itself for capacity delivery requirements. In the energy planning world, the RPS or other policy directives require that a certain amount of wind energy be delivered. The wind energy also creates a large pool of low cost energy that may require transmission that must be able to pay for itself to be able to deliver the wind energy. 
Once generation is built or contracted, only the cost of producing energy is considered for operation of the generation. Generation is dispatched from the lowest cost energy producing generators first, then the next and so on in a merit order of cost of production, with wind energy having an assumed production cost of zero.

\section{B. Transmission Planning for Large Amounts of Energy Resources - Economic Planning}

Transmission has an economic value in the Energy Market when low cost energy is delivered to high priced areas. To justify transmission economically, the benefits from the difference in the price of energy between the low cost area and the high priced area has to be greater than the annual capital and operating cost of the transmission overlay. To make this happen, usually a low cost of transmission per unit of energy delivered and a large volume of energy are required to pay for a transmission overlay.

Studies indicate that transmission overlay designs whose benefits are greater than their costs can be developed for the U.S. Eastern Interconnection for wind energy penetration levels from 5\%-20\%. In Europe, cost/benefit considerations of transnational transmission development at European scale have mainly focused on increasing capacity of existing cross border and national transmission corridors (EWIS [1], ENTSO-E [2], TradeWind [3]). Currently, a discussion on a European supergrid has started inside ENTSO-E.

A special case is the development of a transnational offshore grid in Northern Europe combining the functions of electricity trade and offshore wind power connection, which would involve the construction of new transmission highways for accessing renewable generation. Because of the specific geographic situation where the North Sea wind resources are located surrounded by the demand markets UK-IE, Nordic area and Northern Europe, a substantial part of the solution for accessing the offshore wind power would already be provided by better interconnecting the three above mentioned regions [4], as shown in Fig. 1.

Several models applying optimisation methods to network integration of wind power have also been proposed - modelling wind characteristics generally necessitates the use of stochastic programming techniques. These optimisation models will be inevitably larger in size and complexity due to greater diversity in power flow situations with many spatially distributed and temporally fluctuating generation sources. Pragmatic modelling approaches [6] and model size limitation, combined with model decomposition techniques [7] will help to make this class of problem more computationally tractable.

\section{REGIONAL PLANNING EFFORTS - STATUS AND PROSPECTS}

In the following Cases $\mathrm{A}-\mathrm{H}$, cost effective expansion alternatives are identified by comparing the difference between ideal power flows from an economic analysis (or "market model") of energy resources, and the constrained power flow actually possible through the network. Detailed market models are used and incorporate - in addition to fuel cost minimization - emissions and start-up costs, scheduled and unscheduled outages of plants, and operational constraints [8]. Different generation and exchange market designs and intervals (daily, inter-day, hourly) can also be considered, as in Case $G$ of this section. The more sophisticated market models are merged with a network model (Cases A, B, E). A 
variety of planning approaches, including static [9] and dynamic $[10,11]$ can be used, including hourly flows on an annual basis [12], as illustrated in the variety of case studies below.

\section{A. Eastern Interconnection Joint Coordinated System Plan (JCSP) [13]}

Transmission overlays have to be economical as well as reliable. Three west-to-east HVDC lines nominally scheduled at $75 \%$ of rating, with three terminals per line, cross-linked with $765 \mathrm{kV}$ AC for north-south connections, have been shown to form a self-contingent design that does not adversely impact the underlying $A C$ system.

Over 300 constraints on the underlying system are mitigated or removed by the transmission overlay. Designing a system with a few lines is more economical and simpler to implement than upgrading 300 constraints simultaneously. The JCSP provided for an HVDC overlay consisting of seven lines, as shown in Fig. 2.

The estimated cost for the economic transmission in the $5 \%$ wind scenario in the JCSP study is $\$ 50 \mathrm{~B}$, with a benefit to cost ratio of 1.4 to 1 . The annual cost of the economic transmission is $1 \%$ of the total cost of energy delivered (annual capital, fuel, O\&M and transmission costs). Corresponding numbers for the $20 \%$ scenario are $\$ 80 \mathrm{~B}$ capital cost, with a benefit to cost ratio of 1.7 to 1 , and $2 \%$ annual cost.

\section{B. Eastern Wind Integration and Transmission Study [14]}

The US Department of Energy issued a report in the spring of 2008 that sketched the broad outlines of what supplying $20 \%$ of the annual electric energy demand from wind generation would look like. The Eastern Wind Integration and Transmission Study (EWITS) was a direct follow-up to that effort, charged with exploring many of the technical details that could not be addressed in detail in the initial summary report.

The study looked at costs and transmission associated with increasing wind capacity to $20 \%$ and $30 \%$ of retail electric energy sales in 2024 for the study area, which includes MISO, PJM, SPP, NYISO, ISO-NE, and TVA.

The key transmission issues addressed by the study were an examination of the benefits from long distance transmission that moves large quantities of remote wind energy to urban markets, while accessing multiple wind resources that are geographically diverse. Tradeoffs between remote and local wind resources were also made.

Specific findings and conclusions from development of the transmission overlays for each scenario include the following:

- $\quad$ 800-kV HVDC and EHV AC lines are preferred, if not required, because of the volumes of energy that must be transported across and around the interconnection, as well as the distances involved.

- $\quad$ The modeling indicates that significant wind generation can be accommodated as long as adequate transmission capacity is available. 
- $\quad$ Transmission offers capacity benefits in its own right, and enhances wind generation's contribution to reliability by a measurable and significant amount.

\section{Electric Reliability Council of Texas (ERCOT) [15]}

Texas Senate Bill 20 in 2005 was designed to break the impasse between wind generation development and transmission construction, instructing the Public Utility Commission of Texas (PUCT) to designate areas of the state as Competitive Renewable Energy Zones (CREZ) and, prior to construction of wind generation resources, to order specific transmission improvements to connect these areas to major load centers.

Almost three years and a half later, the PUCT designated five CREZ, spanning much of West Texas from Amarillo to McCamey, and ordered \$5 billion of transmission improvements to move wind generation from the CREZ to load centers (see Fig. 3). Based on planning studies, these transmission improvements are expected to provide adequate capacity for over $18,400 \mathrm{MW}$ of wind generation in West Texas.

The PUCT also designated transmission companies to build these lines and set a deadline for plan completion of December, 2013 - allowing the selected companies less than four years to route, permit, and build over 2,300 circuit miles of new 345-kV transmission.

\section{Iberian Peninsula (Spain and Portugal)}

The European Council set a target of $20 \%$ share of renewable energies in EU energy consumption by 2020. In terms of electricity in Spain, $40 \%$ should be generated by renewable power stations The Spanish target by 2020 is $40 \mathrm{GW}$ in onshore wind power, together with $5 \mathrm{GW}$ in offshore wind power plants. Therefore, the transmission network must be updated to integrate new renewable power stations. The Spanish TSO, REE, is planning an investment of 8,000 M€ during 2007 - 2016, as shown in Table I.

Power system design and operation has been conducting through different scenarios in 2016. The study [16] was conducted in a summer demand situation with a seasonal non-extreme peak level of $92 \%$. Spain is divided in four zones to study the influence of wind power in the transmission system. Wind power generation is set up to $80 \%$ of the installed capacity in the studied zone, while the wind power generation in the other three zones is fixed according to studies of statistical production data. Load flow, short circuit and stability studies were conducted to study network contingency situations and system recovery after a disturbance $[17,18]$. The planned power generation must be capable of providing mainly dynamic voltage control, given the massive penetration of these new technologies. These studies were conducted in peak demand scenarios. Voltage regulation and frequency control studies were conducted in valley demand situations $[19,20]$.

The study concludes that the planned wind power capacity can be integrated into the Spanish power system, highlighting some prerequisites such as the development of the planned transport network and compliance with the actual and proposed technical grid code requirements. Some significant challenges remain in the areas of dynamic voltage control and management of reserves. 
In Portugal, the transmission network planning and operation is a Governmental concession to the TSO, Redes Energéticas Portuguesas, S.A. (REN). REN implemented the Governmental targets to install 6.9 GW of wind capacity until 2020 to ensure $45 \%$ of the consumed electricity by RES.

The TSO plan of investments for 2006-2010 includes $300 \mathrm{~km}$ of very high voltage transmission lines, construction and reinforcement of substations and the operation of phase shift transformers. Fig. 4 depicts the lines driven by independent power producers (IPPs, mainly wind and hydro) with a share ranging from $100 \%$ to $25 \%$. REN followed the recommend methodologies [23] to assess the impact of the spatial distribution of the wind generation as shown in Fig. 5.

In view of the large wind capacity forecasted for the Iberian Peninsula, the Portuguese TSO assessed the transient stability of the system using high probability scenarios [24], required local voltage regulation and started to operate a significant part of the wind generation using "Wind Cluster Control Centers" with power control capabilities.

\section{E. German dena Grid Study II}

[The German dena Grid Study II - initiated by the German Energy Agency (Deutsche Energie-Agentur $\mathrm{GmbH}$ (dena)) and published in November 2010 - focuses on the requirements for a reliable power supply system in 2020 when $39 \%$ of the gross electricity consumption is assumed to be contributed by renewable energy sources [25]. Within this scenario onshore and offshore wind energy installations amount to about $49 \%(37 \mathrm{GW})$ and $18 \%(14 \mathrm{GW})$ of the total installed renewable energy generation capacities. The requirements for a secure grid integration of all temporally available renewable energies are identified in conjunction with a market-driven operation of the present power plant fleet and a liberalized European energy market. Apart from the common estimation of the grid extension requirements different transmission technologies have been evaluated. A special focus lies on investigations of flexible line management (FLM) using line ratings based on actual wind speeds and conductor temperature, and high-temperature conductors (TAL) to increase the transmission capacity of overhead lines in the extra high voltage grid, as shown in Fig. 6.

The large-scale use of FLM and TAL are not economically viable, but for individual cases both technologies can contribute to cover the additional wind based transmission requirements.

\section{F. Transmission Planning in the European North Sea}

Europe is set to build large amounts of offshore wind power, increasing from $2.5 \mathrm{GW}$ today up to 40-85 GW in the year 2030; some of it will be located far from shore with the need for long subsea power cables to the onshore power system. At the same time there is a need to better integrate the power markets in Europe by increasing the transnational power exchange capacity. Both developments call for consideration of combining offshore wind power grid connection and interconnections between countries.

In December 2010 a Memorandum of Understanding was signed by the 10 countries around the North Seas, represented by their energy ministries, their TSOs (organized in ENTSO-E) and their regulators 
(organized since March 2011 in ACER), and the European Commission, forming together the NSCOGI. The objective of this cooperation is to coordinate efforts towards necessary investigations on technical and grid planning questions, as well as identifying market and regulatory barriers, which then should be removed as far as possible.

A new optimization tool for transmission expansion planning has been developed [26]. The tool can - in contrast to previous models - account for the stochastic properties of wind power distributed over large areas. The tool explicitly considers the benefit of transmission capacity between differently priced areas and the value of connecting offshore wind power to the grid versus the investment cost of power cables. The outcome is an optimal grid that answers the question of where to build the new transmission lines/cables and with how much capacity. This tool has been applied to a case study of the North Sea region where there exists extensive plans for both offshore wind development and new subsea interconnectors between countries. In the study, 33 prospective interconnectors were considered; Fig. 7 shows the resulting optimal meshed grid.

\section{G. Cross Border Transmission in Europe: TradeWind}

As Europe is heading for a $25 \%$ share of the electricity demand covered by wind power in 2030 [27], cross-border transmission capacity needs to be significantly increased in several corridors, bringing significant economic benefits in terms of reduced operational costs of power generation. This is the conclusion of the TradeWind study [3], after simulating power flows in the European transmission network with the expected wind power capacity deployment scenarios in 2010, 2015, 2020, reaching 300-400 GW in 2030. Increasing wind power capacity in Europe was found to lead to increased cross border energy exchanges and more severe cross-border transmission bottlenecks in the future, especially with the amounts of wind power capacity in 2020 and 2030.

If the 42 identified onshore and offshore cross-border transmission upgrades are implemented, operational costs of power generation would be reduced by 1.5 Billion $€$ per year (after 2030). TradeWind also evaluated the effect of improved power market rules and quantified these in terms of reduction of the operational costs of power generation. The establishment of intra-day markets for cross-border trade is found to be of key importance for market efficiency in Europe as it will lead to savings in system costs in the order of EUR 1-2 Billion per year as compared to a situation where crossborder exchange must be scheduled day-ahead. Consequently, the TradeWind analysis concluded that the European electricity market needs intraday rescheduling of generators and trade, a consolidation of market areas, and increased interconnection capacity in order to enable efficient wind power integration.

\section{H. European Wind Integration Study Results}

The EWIS study [1] is the first time that a year-round market analysis (necessary to represent the effects of wind on a pan-European basis) has been coupled with detailed representations of the networks (necessary to comprehensively address network performance limitations and so ensure reliability and economy). A key recommendation from EWIS is that pan-European modeling, coordinated and adjusted by more precise regional or national models, should be further developed and used as appropriate to 
assess future development of the European transmission network, especially as the proportion of wind generation increases. This task is being pursued by ENTSO-E.

Looking beyond the immediate measures to strengthen and make best use of existing networks, EWIS also examined the benefits of enhancing cross-border interconnection capacity and identified those links which are likely to have congestion reducing benefits that exceed the likely capital costs. These are illustrated in Fig. 8 and include some 30 links with a total capital cost of circa $€ 12 b$.

\section{System Development in the frame of ENTSO-E}

According to the European EU Regulation 714/2009 a common body of the European Transmission system operators have been installed representing 42 TSOs from 34 countries. In this area there is 828 GW generation capacity covering 3,400 TWh of demand. The TSOs own and operate a grid with a length of 305,000 km lines inside 5 synchronous zones. According to European regulations the TSOs are obliged to publish every second year a plan on the next ten years' grid development - the Ten-Year-NetworkDevelopment-Plan (TYNDP). A first pilot plan has been published in March 2010 [2].

The main drivers behind these transmission planning needs are a lot of wind power in northern Europe, some hydro power in northern and central Europe, and a lot of solar power expected in southern Europe. Additionally, some conventional power plants are being decommissioned, some new will be built, and some demand will change, resulting in changing flow patterns, leading to a need for transmission lines. Summarizing, there are three main reasons for transmission needs: security of supply, connection of renewables and implementation of the market.

\section{LOOKING INTO THE FUTURE}

In the near term in the US, meeting the ambitious targets that have been set for renewable energy will require the upgrading of existing lines and the construction of new ones. Because of the long distances and the multiple state and regional boundaries that must be crossed to move the renewable energy to market, as well as the critical national security and long-term environmental sustainability issues involved, it is clear that there is an appropriate role for the federal government. Legislation has been introduced which requires interconnection-wide transmission planning to be performed, an interconnection-wide cost allocation for high voltage backbone transmission line costs, and federal backstop authority for transmission line siting. It is not clear if or when such legislation will be passed, but it is an indication of the growing importance with which the critical need for an expanded transmission infrastructure is being viewed.

Similar discussions are being held in European countries and at the EU level. As in the US, there is a growing consensus at the political levels that increased transmission is essential for reaching the renewables targets, and that there is a strong role for a coherent European policy. Traditionally (in the former decade) cross border transmission planning at a European scale was linked to the development of a single internal market for electricity. More recently, the European Commission has produced a new "European Energy Infrastructure Package" to facilitate the realization of the renewables targets of the Commission (20\% renewables by 2020 ), including a blueprint for an offshore grid in Northern Europe. 


\section{ACKNOWLEDGMENT}

The authors would like to acknowledge the contributions of their many professional colleagues working in the wind integration and transmission planning field, who have contributed to the thinking and progress reported here.

\section{References}

[[1] European Wind Integration Study. EWIS Final Report. March 2010

[2] 10 Year Network Development Plan 2010-2020. ENTSO-E March 2010. available at: www.entsoe.eu

[3] EU-IEE project TradeWind. Available at http://trade-wind.eu

[4] A. Woyte, J . De Decker, V. V. Thong, 2008. A North Sea Electricity Grid [R]evolution: Electricity Output of Interconnected Offshore Wind Power, a Vision of Offshore Wind Power Integration. Greenpeace - 3E. Available at www.greenpeace.org

[5] EWEA: Oceans of Opportunities (2009)

[6] D.J.Burke, "Accommodating wind power characteristics in power transmission planning applications", PhD Thesis, University College Dublin, Dublin, Ireland 2010. Available online - 
http://erc.ucd.ie/files/theses/Daniel\%20Burke\%20\%20Accommodating\%20Wind\%20Energy\%20Characteristics\%20in\%20Power\%20Transmission\%20Plann ing\%20Applications.pdf

[7] D.J. Burke and M.J. O'Malley, 'A study of optimal non-firm wind power connection to congested transmission networks' IEEE Transactions on sustainable energy, vol.2, no.2, pp167-176, April 2011

[8] M.P. Padhy, "Unit Commitment - A Bibliographical Survey", IEEE Transactions on Power Systems, 19(2): $1196-1205$, May 2004

[9] G. Latorre, R.D. Cruz, J.J. Areiza, A. Villegas: Classification of Publications and Models on Transmission Expansion Planning, IEEE Transactions on Power Systems, Vol. 18, No. 2, May 2003, pp. 938-946.

[10] R. Romero, A. Monticelli, A. Garcia, S. Haffner, "Test systems and mathematical models for transmission network expansion planning",IEE Proceedings-Generation, Transmission and Distribution. Vol 149, No 1, pg 27-36, 2002

[11] A. L'Abbate, I. Losa, G. Migliavacca, , A.R Ciupuliga, M. Gibescu, H. Auer, K. Zach. "D3.3.1 Possible criteria to assess technical-economic and strategic benefits of specific transmission projects" Realisegrid Deliverable, available on http://realisegrid.rse-web.it/

[12] A.R. Ciupuliga, M. Gibescu, E. Pelgrum, P.G.H Jacobs., C.P.J. Jansen, and W.L. Kling, "Round-the-year Security Analysis with Bottleneck Ranking for Interconnected Power Systems with Large-Scale Wind Power", Innovative Smart Grid Technologies Conference Europe (ISGT Europe), 2010 IEEE PES

[13] Joint Coordinated System Plan. Joint Coordinated System Plan 2008. https://www.midwestiso.org/Planning/Pages/StudyRepository.aspx

[14] Eastern Wind Integration and Transmission Study website. [Online]. Available: http://wind,nrel.gov/public/EWITS/

[15] Electric Reliability Council of Texas (2006). Analysis of Transmission Alternatives for Competitive Renewable Energy Zones in Texas. http://www.ercot.com/news/presentations/2006/ATTCH_A _CREZ_Analysis_Report.pdf.

[16] A. Clavero, S. Martínez, F. Rodrígruez-Bobada, "Estudios de integración de generación de régimen especial en 2016 en el sistema eléctrico peninsular español". XIII Encuentro Regional Iberoamericano de Cigré, Argentina, 24-28 May 2009.

[17] REE/REN 2005. Estudio de Estabilidad Eólica de la Península Ibérica Síntesis de Criterios y Metodologías, REE / REN. May, 2005.

[18] F. Rodríguez-Bobada, A. Reis Rodriguez, A Ceña, E. Giraut, "Study of wind energy penetration in the Iberian peninsula". European Wind Energy Conference (EWEC), 27 February - 2 March, 2006, Athens, Greece. 
[19] Red Eléctrica y Empresas Eléctricas, "Criterios Generales de Protección del Sistema Eléctrico Peninsular Español", 1995

[20] F. Rodríguez-Bobada, P. Ledesma, S. Martínez, L. Coronado and E. Prieto "Simplified Wind Generator Model for Transmission System Operator Planning Studies", International Energynautics Workshop on Large Scale Wind Integration. Madrid, May, 2008

[21] Plano de investimento e desenvolvimento da rede de transporte 2009-2014 (2019), REN-Rede Eléctrica Nacional, February 2008, pp243. Available at: www.ren.pt

[22] Plano de investimento da rede de transporte 2006-2011, Vol.1 REN-Rede Eléctrica Nacional, Nov. 2005, pp180. Available at: www.ren.pt

[23] Simoes, T.; P. Costa and A. Estanqueiro. A methodology for the identification of the sustainable wind potential. The Portuguese case study. IEEE Power Systems Conference and Exposition, 2009. PSCE apos;09. IEEE/PES Volume , Issue , 15-18 Março 2009 Page(s):1 - 7 ISBN: 978-1-4244-3810-5.

[24] Sucena Paiva, J.P.; J.M. Ferreira de Jesus; Rui Castro; Pedro Correia; João Ricardo; A. Reis Rodrigues; João Moreira and Bruno Nunes, "Transient stability study of the Portuguese transmission network with a high share of wind power", XI ERIAC CIGRÉ - Undécimo Encuentro Regional Iberoamericano de Cigré, Paraguay, May 2005

[25] German Energy Agency (dena): "dena Grid Study II - Integration of Renewable Energy Sources in the German Power Supply System from 2015 - 2020 with an Outlook to 2025 - Summary of the main results by the project steering group", Berlin, 2010

[26] Thomas Trötscher, Magnus Korpås (2011) A framework to determine optimal offshore grid structures for wind power integration and power exchange, Wind Energy, DOI: 10.1002/we.461

[27] European Wind Energy Association (EWEA), 2009. Pure Power: Wind Energy Scenarios up to 2020. Available at www.ewea.org

Figure captions

Fig. 1 EWEA 2030 offshore grid vision [5]

Fig. 2. JCSP HVDC overlay]

Fig. 3. Texas CREZ locations

Fig. 4 - RES driven transmission lines included in the PT RNT Plan of Investments (2006-2010) [21].

Figure 5 - Spatial distribution of the wind power to be injected in the transmission substations [22].

Fig. 6: Grid extension and annual costs of the different technologies: Basic grid with standard transmission capacity (Basic); Flexible line management (FLM); High-temperature conductors (TAL) [adapted from [25]] 
Fig. 7. Optimal grid example for the North Sea region. Green - optimized interconnectors; red - existing interconnectors; blue triangles - major offshore wind farms.

Fig. 8. Cross-border reinforcements with potentially strong economic benefits

Tables

TABLE I

\begin{tabular}{lcccccc}
\multicolumn{8}{c}{ PLANNED ELECTRICAL CIRCUITS IN THE SPANISH TRANSMISSION SYSTEM } \\
\hline Lines and cables & Total & $400 \mathrm{kV}$ & $220 \mathrm{kV}$ & Total & $400 \mathrm{kV}$ & $220 \mathrm{kV}$ \\
New circuits km & 12656 & 7488 & 5168 & 4465 & 3504 & 961 \\
Refitting km & 8308 & 3850 & 4458 & 1730 & & \\
\end{tabular}

Further Reading/Resources

J. Grainger and W. Stevenson, Power System Analysis, McGraw-Hill, New York, 1994.

R.D. Christie, B.F. Wollenberg, and I. Wangensteen, "Transmission

management in the deregulated environment", Proceedings of the IEEE,

Vol 88, No.2, pg.170-195., 2000.

ENTSO-E, "Definitions of Transfer Capacities in Liberalized Electricity

Markets", available at https://www.entsoe.eu.

NERC, "Documentation of Total Transfer Capability and Available

Transfer Capability Calculation Methodologies", Standard MOD-001-0,

Princeton: North American Electric Reliability Corporation (2005).

P. Kundur, Power System Stability and Control. McGraw-Hill, 1997.

M. Zima, M. ; G. Andersson, "On security criteria in power systems

operation". Power Engineering Society General Meeting, 12-16 June 2005.

Related Articles

Article ID

Article title 


\begin{tabular}{|l|l|}
\hline WENE-169 & What Justifies Transmission Grid Investments? \\
\hline WENE-179 & Renewable Energy Systems and their Integration \\
\hline & \\
\hline
\end{tabular}




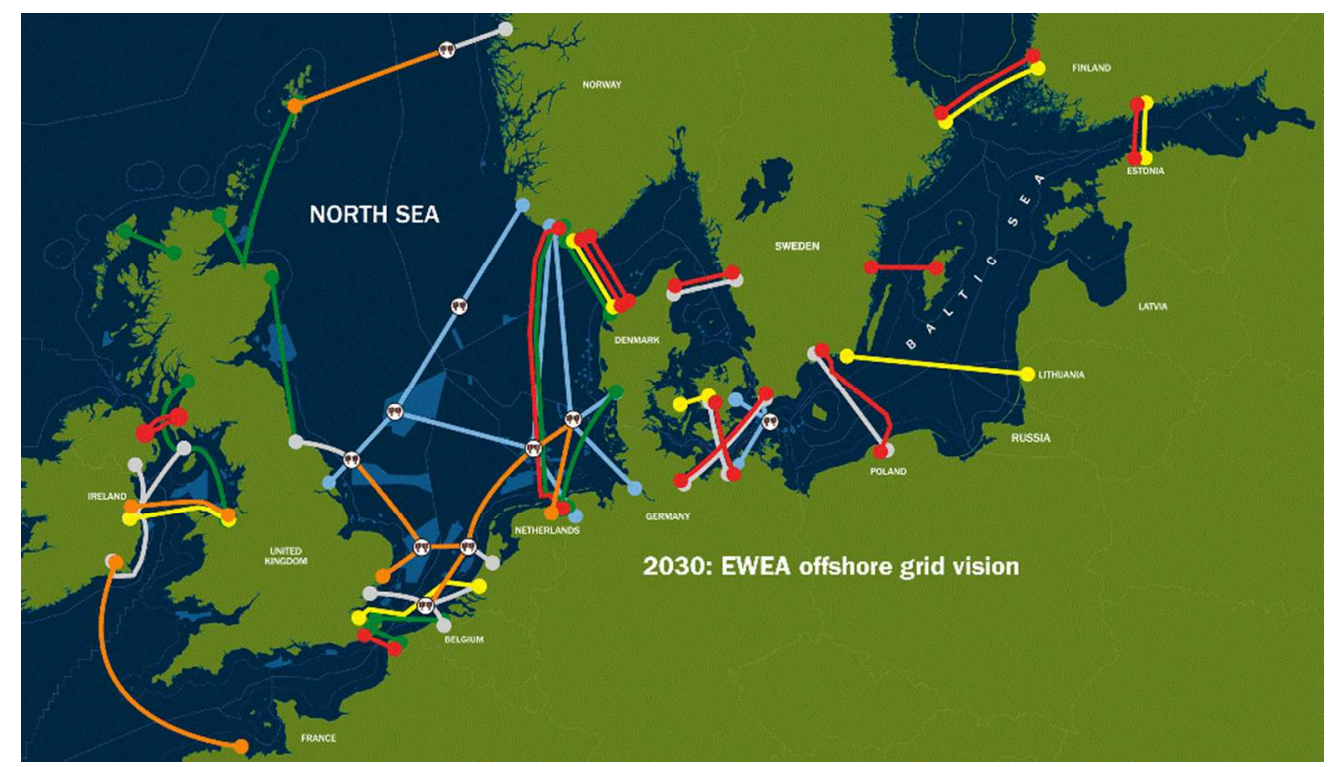

Figure 1

264x152mm (96 x 96 DPI) 


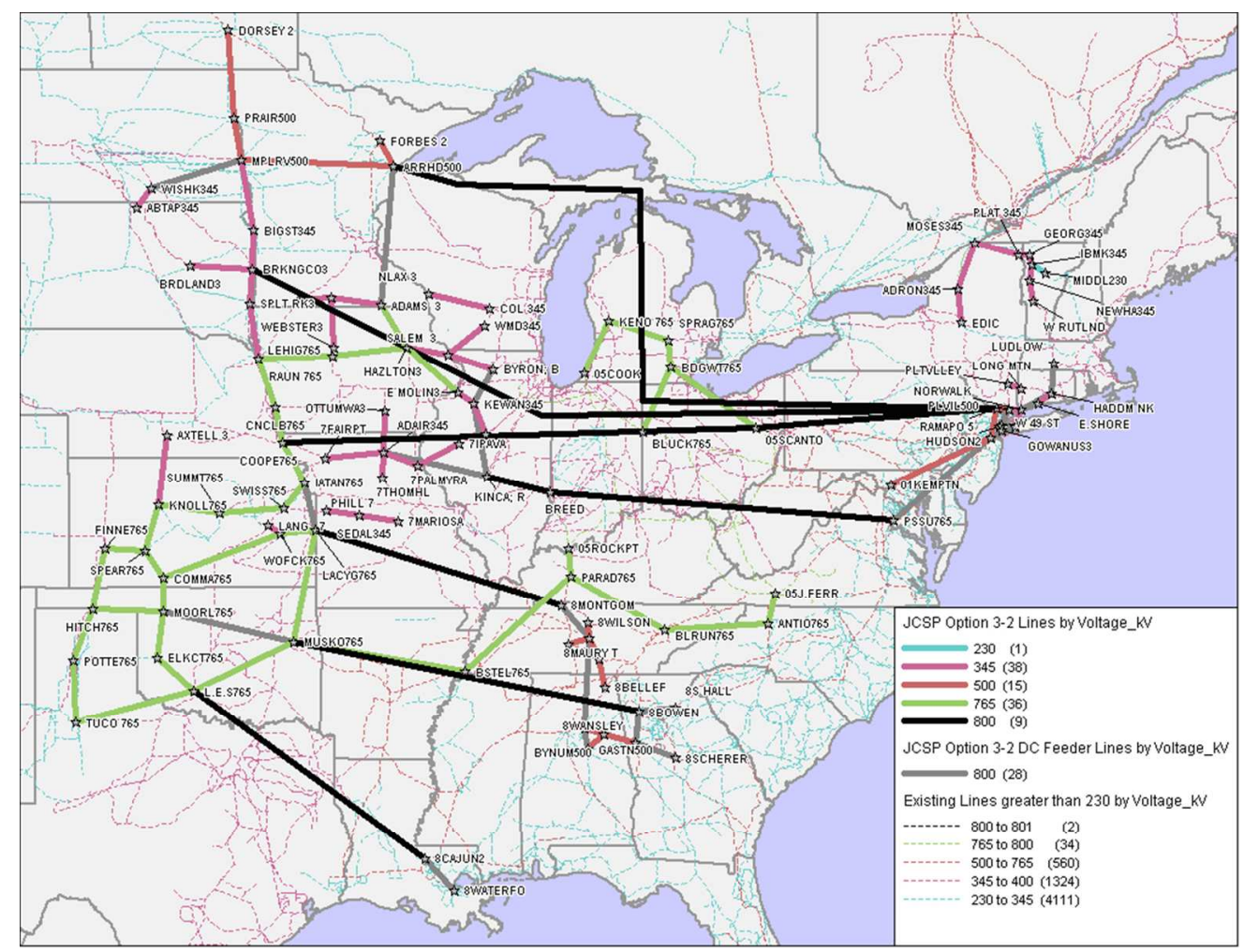

Figure 2

$265 \times 203 \mathrm{~mm}(96 \times 96 \mathrm{DPI})$ 


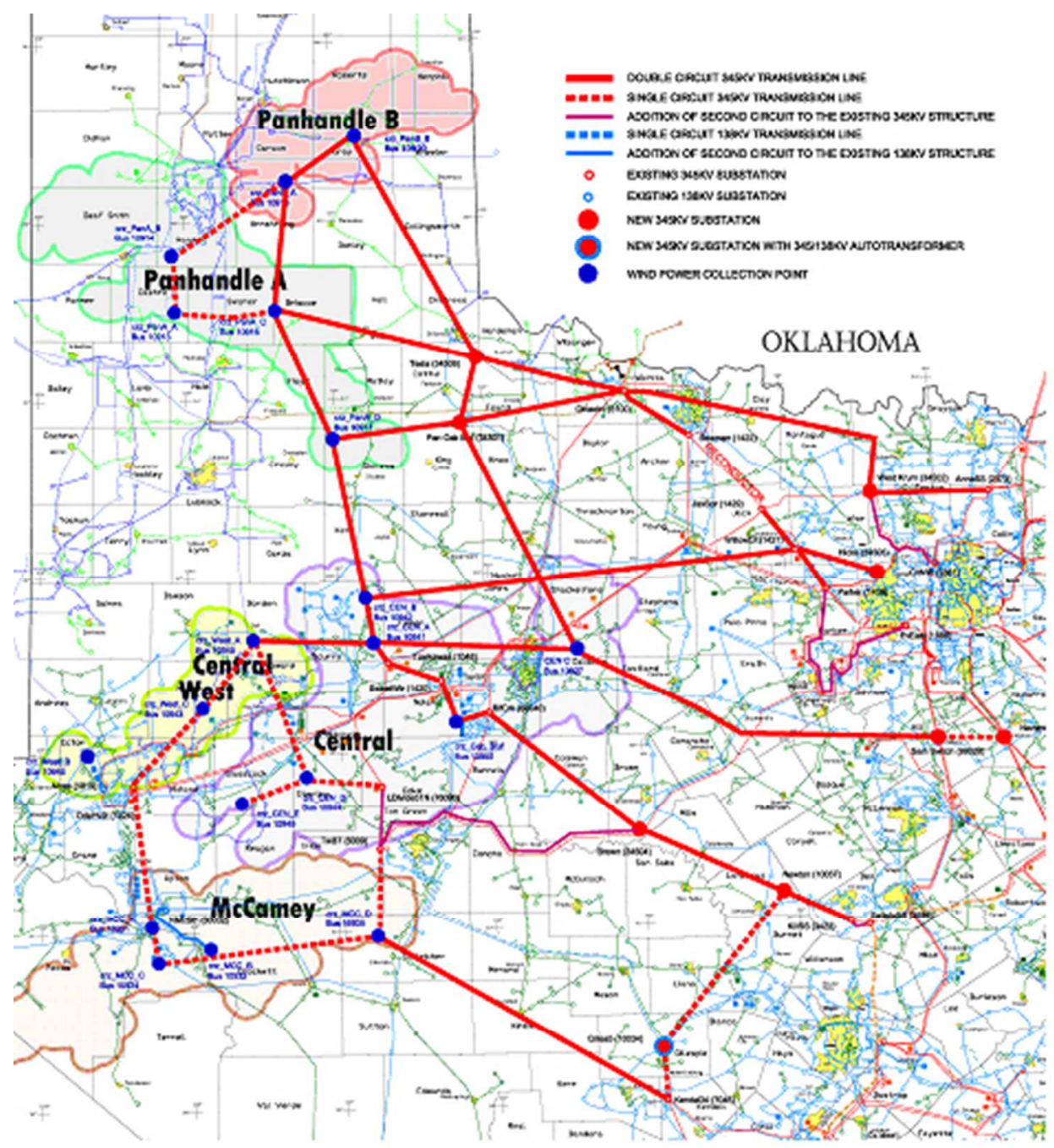

Figure 3

$166 \times 180 \mathrm{~mm}(72 \times 72$ DPI $)$ 


1
2
3
4
5
6
7
8
9
10
11
12
13
14
15
16
17
18
19
20
21
22
23
24
25
26
27
28
29
30
31
32
33
34
35
36
37
38
39
40
41
42
43
44
45
46
47
48
49
50
51
52
53
54
55
56
57
58
60

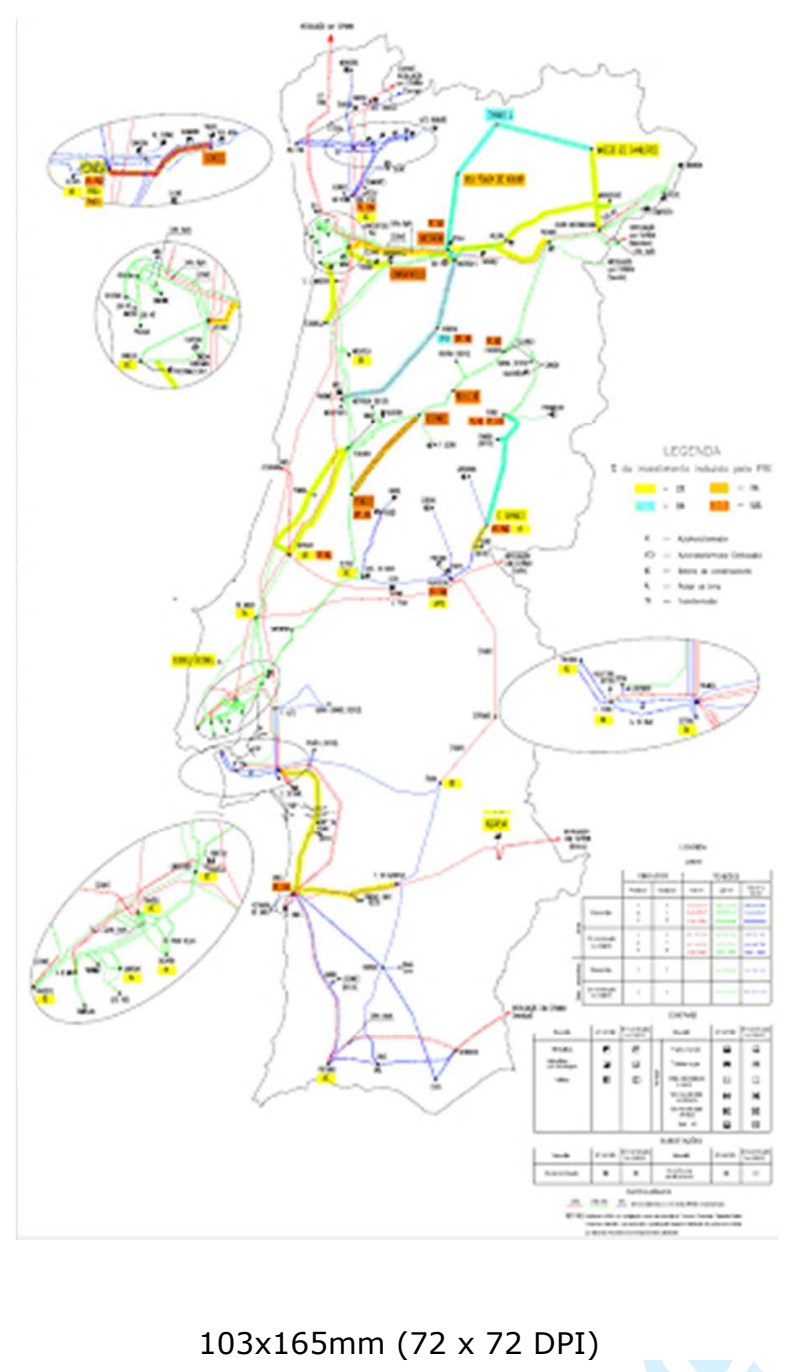

John Wiley \& Sons 


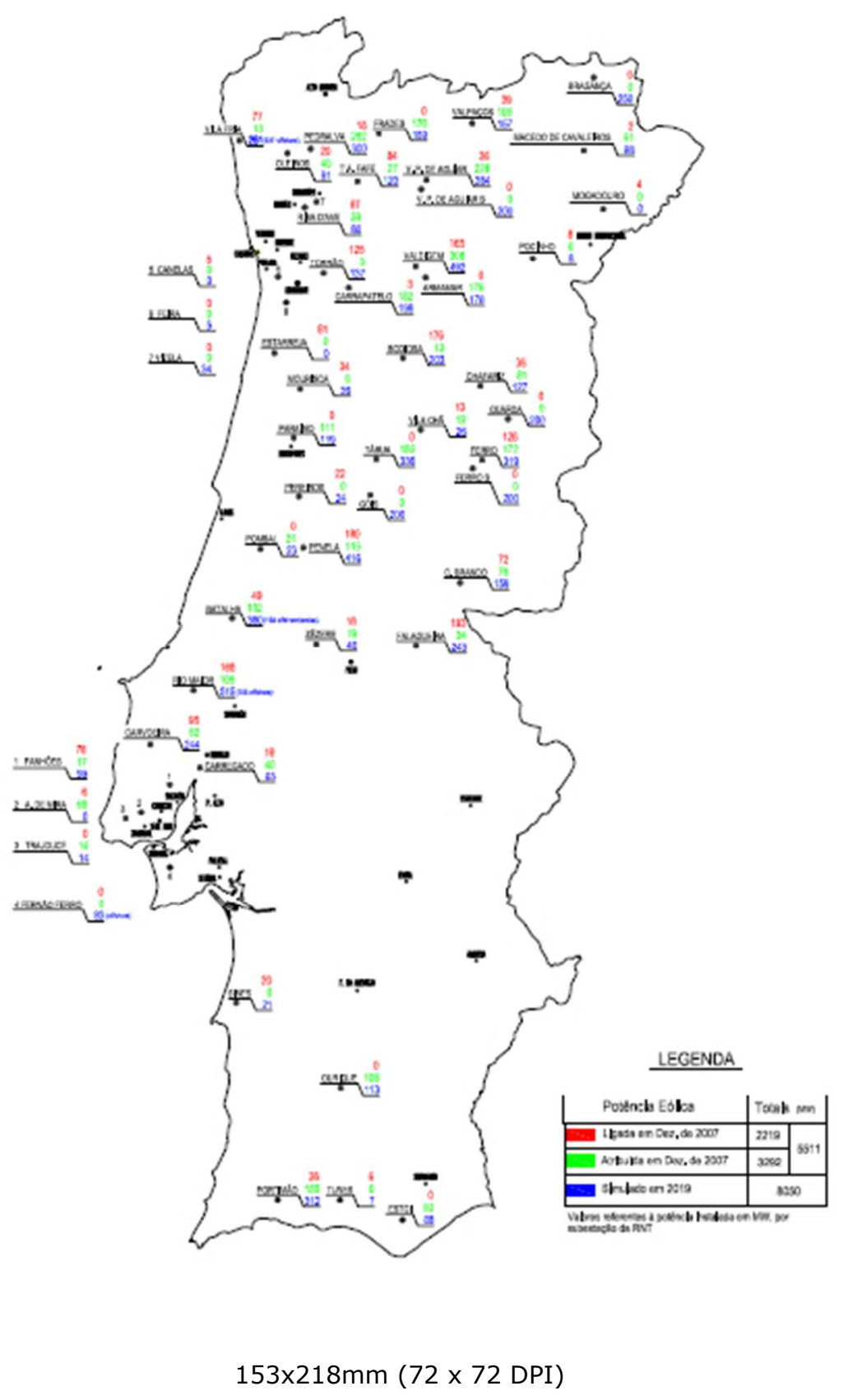

John Wiley \& Sons 


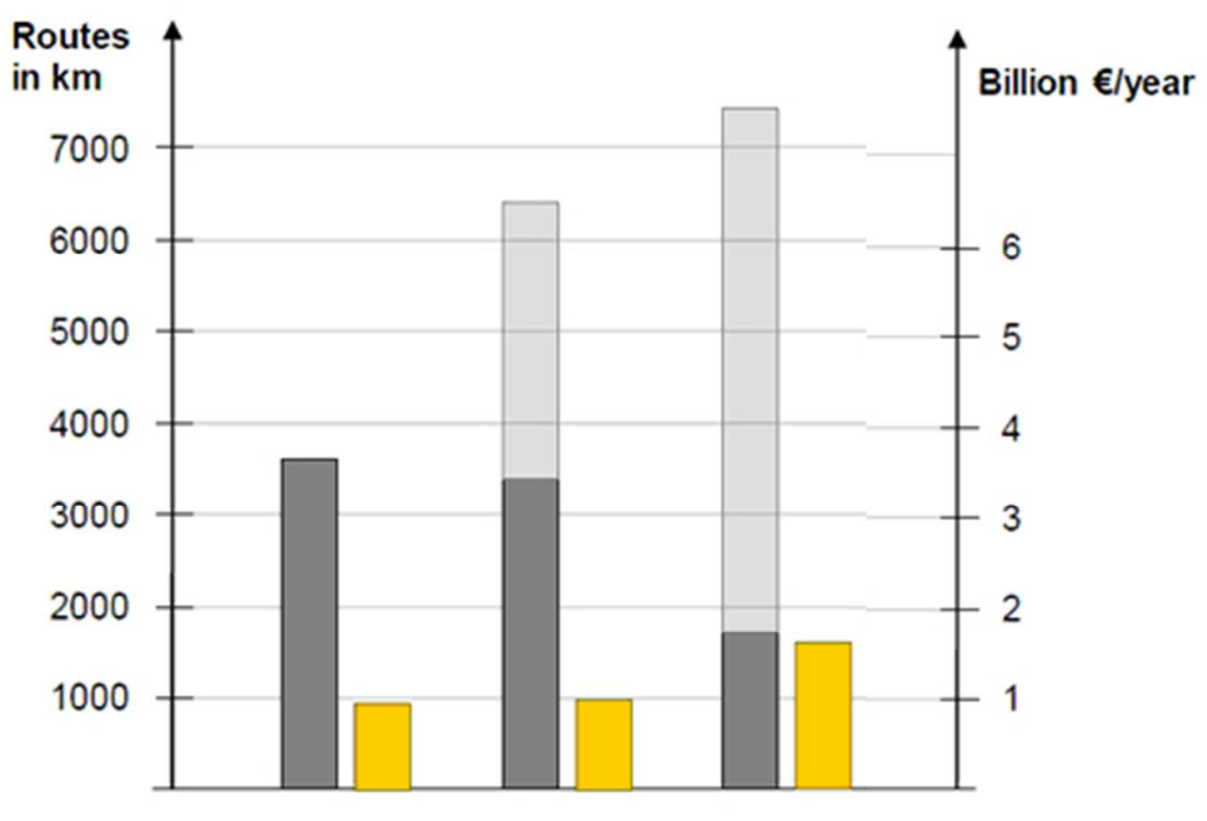

\section{Basic FLM TAL}

$\square$ New overhead line routes

$\square$ Modification of overhead line routes (i.e. structural changes to existing routes)

New underground cable routes

$\square$ Costs per year (annualised capital and operating costs)

Figure 6 $186 \times 162 \mathrm{~mm}(72 \times 72 \mathrm{DPI})$ 


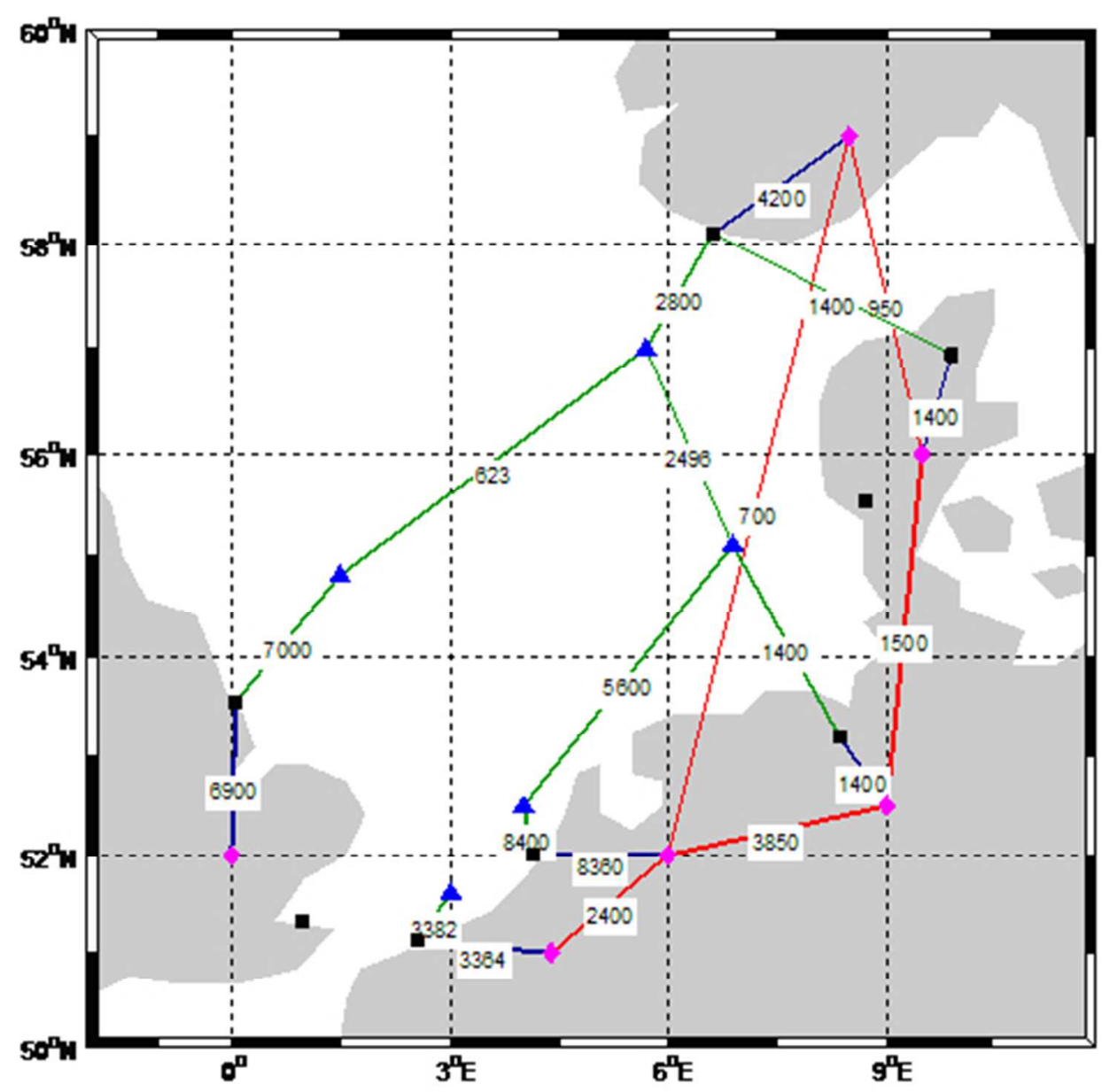

$172 \times 167 \mathrm{~mm}(72 \times 72$ DPI $)$

John Wiley \& Sons 


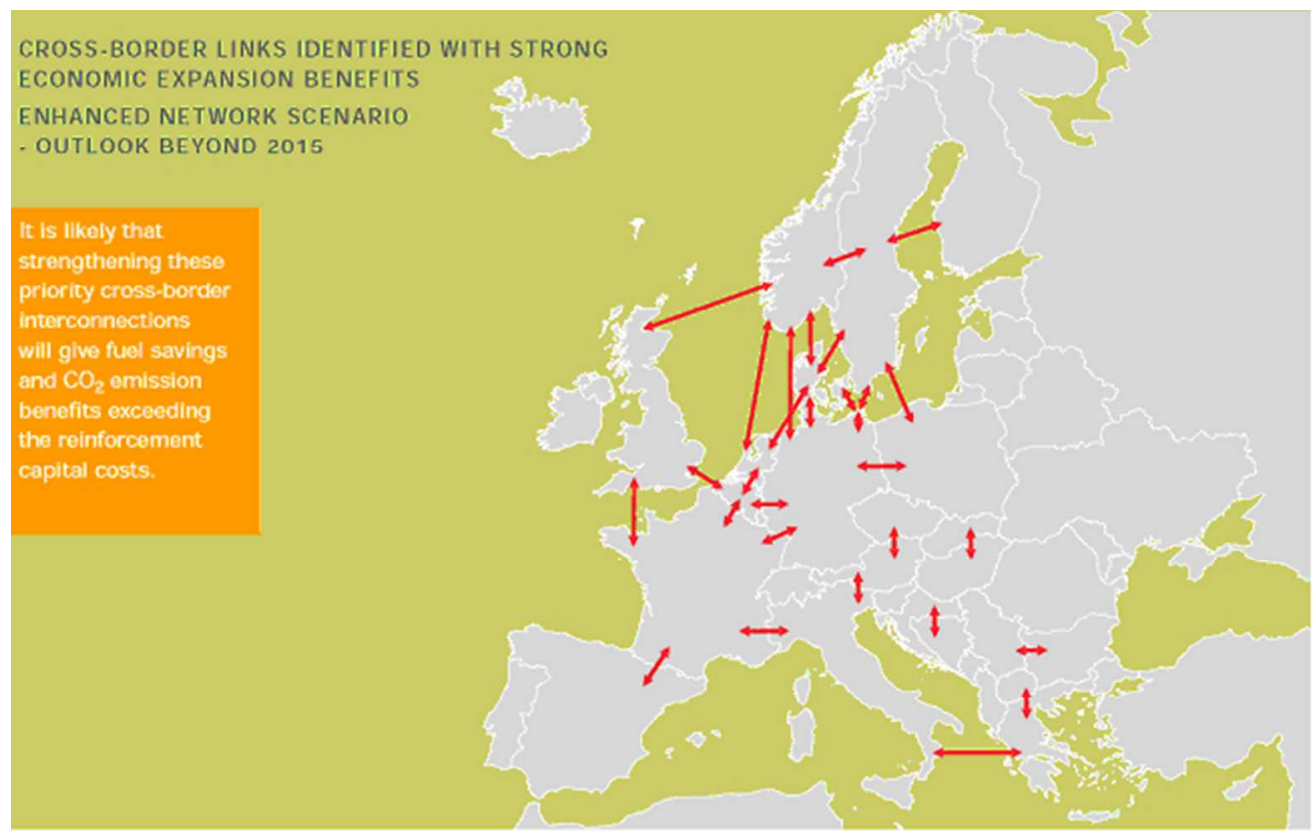

$228 \times 144 m m(72 \times 72$ DPI $)$ 